\title{
Microbial production of melanin and its various applications
}

\author{
Anh N. Tran-Ly ${ }^{1,2} \cdot$ Carolina Reyes $^{1} \cdot$ Francis W. M. R. Schwarze ${ }^{1} \cdot$ Javier Ribera $^{1}$ D
}

Received: 17 July 2020 / Accepted: 24 September 2020 / Published online: 12 October 2020

(c) The Author(s) 2020

\begin{abstract}
Melanins are natural biopolymers that are known to contribute to different biological processes and to protect organisms from adverse environmental conditions. During the past decade, melanins have attracted increasing attention for their use in organic semiconductors and bioelectronics, drug delivery, photoprotection and environmental bioremediation. Although considerable advances in these fields have been achieved, real-world applications of melanins are still scarce, probably due to the limited and expensive source of natural melanin. Nevertheless, recent biotechnological advances have allowed for relatively large-scale production of microbial melanins, which could replace current commercial melanin. In this review, we first describe different melanin sources and highlight the advantages and disadvantages of each production method. Our focus is on the microbial synthesis of melanins, including the methodology and mechanism of melanin formation. Applications of microbial melanins are also discussed, and an outlook on how to push the field forward is discussed.
\end{abstract}

Keywords Fungi $\cdot$ Microbial melanin $\cdot$ Pigments $\cdot$ Upscaling

\section{Introduction}

Melanin is an ancient pigment that occurred very early in all living organisms (Zhang et al. 2010; Glass et al. 2012). Melanin is typically known for its unique ability to absorb a wide range of radiations (Brenner and Hearing 2008; Liu et al. 2013). Moreover, melanization is considered a survival strategy for many organisms inhabiting unfavorable environmental conditions. Owing to the multifunctionality of the pigment, it has been known to serve as: (a) an antioxidant and radical scavenger (Ju et al. 2011; Le Na et al. 2019), (b) a photo-protector that efficiently absorbs and dissipates solar radiation in the form of heat (d'Ischia et al. 2015), (c) an absorber that chelates metals and binds organic compounds (Karlsson and Lindquist 2016; Tran-Ly et al. 2020) and (d) an organic semiconductor (Bothma et al. 2008). Besides these functions, melanin is considered eco-friendly

Anh N. Tran-Ly

Anh.Tran-Ly@empa.ch

$\triangle$ Javier Ribera

Javier.Ribera@empa.ch

1 Laboratory for Cellulose \& Wood Materials, Empa, 9014 St. Gallen, Switzerland

2 Department of Civil, Environmental and Geomatic Engineering, ETH Zürich, 8093 Zürich, Switzerland and biocompatible since it is naturally synthesized by most organisms. Melanin has recently burst onto the scene of materials science and green technology as a functional additive or coating that can substantially improve the performance of conventional materials for different applications. However, upscaling production and extraction protocols of melanin needs further optimization so that it can be used for developing novel materials.

In this review, we first introduce the current understanding of melanin, along with its chemical structures and physical properties. We then present the strategies of melanin production, including the chemical synthesis and methods based on natural resources with emphasis on promising biotechnology processes using microorganisms. We highlight several recent applications of microbial melanins, and provide our perspectives on how to bring melanin closer to practical applications in materials science.

\section{Melanin pigments}

Recent studies suggest that melanin is in fact a general term for a group of heterogeneous pigments produced by organisms of all domains of life from bacteria to mammals (the plural form "melanins" is occasionally used in sections below indicating the heterogeneous nature of melanin). In 
humans, melanin is the prominent pigment responsible for the colour of skin, hair and eyes (Solano 2014; d'Ischia et al. 2015). As melanin usually appears black or dark brown, the pigment derives its name "melanin" from "melanos"- an ancient Greek word for black (Borovanskỳ and Riley 2011). However, there are other pigments in this group that produce reddish or yellowish colours such as the pheomelanin found in red hair, freckles, and feathers.

Melanin has a relatively diverse and heterogeneous structure. This is due to the ubiquitous sources of melanin, which leads to its heterogeneity in composition, size, color and function. Moreover, the physicochemical properties of melanin (a highly negative charge, high molecular weight and hydrophobic nature) hinder analytical approaches to identify and characterize its structure (Pralea et al. 2019). Additionally, the pigment is insoluble in most solvents and is resistant to chemical degradation (Nosanchuk et al. 2015; Pralea et al. 2019). Chemical treatments, such as using a strong base, can be used to dissolve melanin but often alter its native structure and may even break the initial polymer into fragments. Enzymatic digestion is relatively inefficient in eliminating the protein and lipid content of natural samples (Pralea et al. 2019).

A widespread definition of melanin is "a heterogeneous polymer derived from the oxidation of phenolic or indolic compounds and subsequent polymerization of intermediate phenols and their resulting quinones" (Solano 2014). Melanin pigments can be categorized based on their chemical structures, namely, eumelanin, pheomelanin, neuromelanin and allomelanin (d'Ischia et al. 2013). Eumelanin is the black-to-brown subgroup of melanin formed by oxidative polymerization of tyrosine derivatives such as L-3,4-dihydroxyphenylalanine (L-Dopa), and it is the most common melanin found in animals, including humans (Solano 2014). Eumelanin is, therefore, by far the most relevant source from a biological and technological perspective and has been widely studied and used as a model for synthetic melanin. Pheomelanin is another type of animal melanin, found in red hair, freckles or feathers, which differs from eumelanin by the presence of sulfur in the composition since its precursor is 5-cysteinyl-Dopa. Neuromelanin is explicitly produced within human neurons by the oxidation of dopamine and other catecholamine precursors. In plants, fungi and bacteria, the identified melanin is called allomelanin. This group encompasses a variety of non-nitrogenous subgroups of melanin derived from different catecholic and dihydroxynaphtalene precursors, which are usually mentioned as catechol melanin (in plants), DHN-melanin and pyomelanin (in bacteria and fungi). Lastly, it is notable that many microorganisms can produce different types of melanin, including eumelanin via a similar pathway with mammalian melanin synthesis (Eisenman and Casadevall 2012; Cordero and Casadevall 2017) (Table 1).

\section{Melanin isolation from conventional natural sources}

Conventionally, melanin is extracted from sepia ink or animals' dark hair/feathers. One of the challenges for melanin production and extraction from these sources is that most melanins are formed inside melanosomes and are tightly bound to some cellular components such as proteins or minerals (Prota 1995). Therefore, the isolation procedure of melanin usually involves harsh chemical treatments to remove the entire protein fraction, cell debris and unconsumed nutrients. Normally, these treatments include extensive hydrolysis with boiling mineral acids or bases followed by successive washing steps with organic solvents such as chloroform, acetone or absolute ethanol (Liu and Simon 2003; Pralea et al. 2019). However, during the latter process, the melanin polymeric skeleton suffers chemical alterations (Pralea et al. 2019). Alternative strategies reported in the literature have described the use of milder isolation methodologies such as: mechanical separation using ultracentrifugation; proteolytic digestion using enzymes to eliminate the residue protein matrix; or a combination of both strategies (Novellino et al. 2000; Xiao et al. 2018) (Fig. 1). Some studies have shown that enzymatic extraction methods can retain the melanin structure and its morphology in the form of intact melanosomes better than the acid/base extraction protocols (Liu et al. 2003).

Natural melanins are complete polymers with limited potential for modification. Besides, the final drying method can have a great influence on the physical properties of melanin such as the aggregation, the surface area-to-mass ratio,
Table 1 Summary of common melanins, sources and their corresponding precursors

\begin{tabular}{lll}
\hline Type of melanin & Producing sources & Melanin precursor \\
\hline Eumelanin (DOPA-melanin) & Animals, bacteria, fungi & Tyrosine or L-Dopa \\
Pheomelanin & Animals & 5-S-cys-Dopa \\
Neuromelanin & Human (brain) & Dopamine and 5-S-cys-dopamine \\
Catechol-melanin & Plants & Catechol \\
DHN-melanin & Fungi, bacteria & 1,8 -dihydroxynaphthalene (DHN) \\
Pyomelanin & Fungi, bacteria & Homogentisic acid \\
\hline
\end{tabular}


Fig. 1 Mild and harsh melanin extraction steps currently used to obtain melanin from living cells

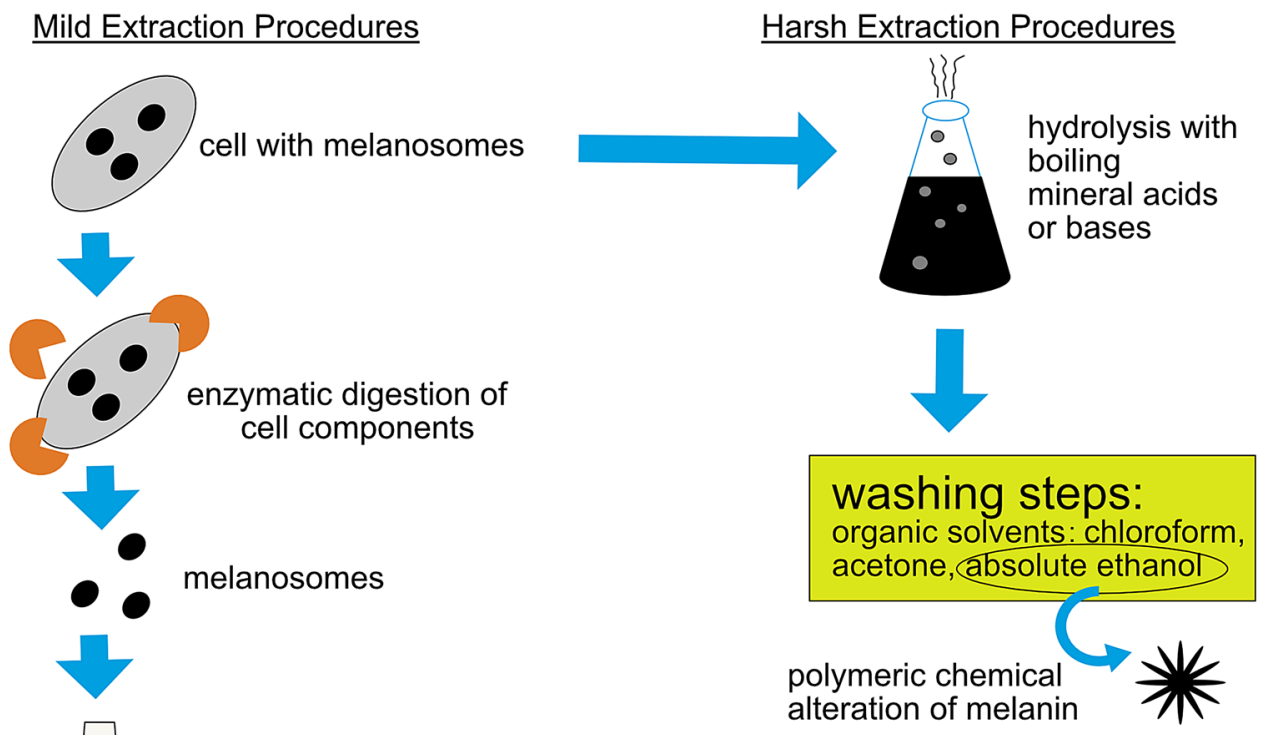

and porosity (d'Ischia et al. 2013). This source-dependency makes natural melanin supply difficult and expensive for up-scaling and can result in contamination depending on its source. For example, melanin extracted from feathers of birds or the ink sac of sepia may have an increased amount of associated toxic metals related to their environmental exposure. Moreover, these melanin sources are of ethical concern as the animals, from which melanin is extracted, may need to be killed. All these factors emphasize the cautious use of natural melanin for applied research.

\section{Melanin production by chemical synthesis}

In the last decade, the synthesis of materials with properties mimicking that of natural melanins has been extensively investigated (Lee et al. 2007; Liu et al. 2013; D' Ischia et al. 2014; Solano 2017). In chemical synthesis, polydopamine, which shares some properties with natural melanin due to their similar functional groups such as catechol, amine and imine groups (Solano 2017), is synthesized via oxidative polymerization of dopamine. The high tunability of polydopamine has rapidly promoted research on this material (Liu et al. 2014). Notably, when studies on synthetic melaninbased materials are cited, they usually refer to polydopamine and its derivatives.

Three common approaches for the synthesis of polydopamine are: (1) solution oxidation, (2) enzymatic oxidation, and (3) electropolymerization (Liu et al. 2014). Solution oxidation under alkaline conditions is widely used and involves the oxidation with oxygen and self-polymerization of the dopamine monomers. The second approach is often related to the enzymatic oxidation of L-tyrosine using the enzyme tyrosinase. Another method in this approach involves the oxidation of diphenolic groups of dopamine, followed by its polymerization into polydopamine using the enzyme laccase. Lastly, the electropolymerization method has mainly been used for the formation of polydopamine on an electrode. In a deoxygenated solution, a polymeric film with high thickness can be effectively obtained by applying an appropriate electrical voltage. One disadvantage of this method, however, is the requirement that the surface of the electrode is conductive, hence polydopamine can only be deposited on conductive materials.

Despite a number of attempts to mimic natural melanins, synthetic melanins often have altered structural and functional properties compared to natural melanins (Ligonzo et al. 2009; Bridelli and Crippa 2010). Some reports have demonstrated that natural melanins in biotechnological applications outperform synthetic melanins. For instance, sepia melanin exhibits a higher specific capacity (16.1 in comparison with $7.9 \mathrm{mAhg}^{-1}$ ) in aqueous sodium-ion batteries compared to polydopamine (Kim et al. 2013). The higher efficiency of natural melanins may be attributed to their innate features, including the carboxyl content of the starting precursor (i.e. tyrosine or L-DOPA vs. dopamine, which is devoid of a carboxylic group), the melanogenesis mechanism (Pezzella et al. 1997), the unique nanostructure of melanin granules attached to small amounts of proteins, and the higher hydration degree of the molecules (Bernsmann et al. 2010). 


\section{Melanin production by microorganisms}

The diverse biological roles of melanin in bacteria and fungi have been extensively reported in the literature (Nosanchuk and Casadevall 2003; Plonka and Grabacka 2006; Eisenman and Casadevall 2012; Solano 2014; Cordero and Casadevall 2017). However, the control of melanin synthesis in different microorganisms has only recently been investigated. Considering the advantages of using microorganisms to produce melanin, such as no seasonal growth constrains, cost-effectiveness, and eco-friendliness, microbial melanin is a valuable source of natural melanin.

Generally, most microbial melanins are formed through the transformation of either tyrosine (DOPA-pathway) or malonyl-coenzyme A (DHN-pathway), facilitated by different sets of enzymes (Fig. 2). The first pathway is very similar to mammalian melanin synthesis. In this pathway, the melanin precursor, tyrosine, is converted to L-Dopa, then to dopaquinone by tyrosinase and laccase. Dopaquinones are highly active and spontaneously oxidized and autopolymerized to form melanin. Synthesis of melanin via the DOPA-pathway is referred to as DOPA-melanin or eumelanin. However, during the catabolic process, other hydroxylated aromatic compounds such as homogentisic acid, can accumulate due to enzymatic imbalances or interruptions, which may result in different types of melanins. In the second pathway, the corresponding precursor, malonyl-coenzyme $\mathrm{A}$, is produced endogenously. Catalyzed by polyketide synthases, the sequential decarboxylative condensation of five molecules of malonyl-coenzyme A creates 1,3,6,8-tetrahydroxynaphthalene (THN). THN then undergoes a series of reduction and dehydration reactions to form 1,8-dihydroxynaphthalene (DHN). The polymerization of DHN results in DHN-melanin as the final product (Plonka and Grabacka 2006; Eisenman and Casadevall 2012; Pavan et al. 2020). Notably, both pathways can be found in bacteria and fungi. Nevertheless, most bacteria and basidiomycetous fungi synthesize melanin via the DOPA-pathway, whereas, ascomycetous and some imperfect fungi including non-microscopic fungi, for instance Tuber spp., use the DHN-pathway to produce melanin.

With respect to high-yield melanin production, microorganisms using the DHN-pathway are not preferred since in this pathway, the pigment is synthesized endogenously and is tightly attached to the inner side of the cell wall (Toledo et al. 2017). This makes melanin extraction extremely difficult and can generate artifacts derived from harsh extracting chemicals. Alternatively, melanogenesis via the DOPA-pathway is a mechanism microorganisms use to neutralize toxic phenolic compounds from the environment, such as those
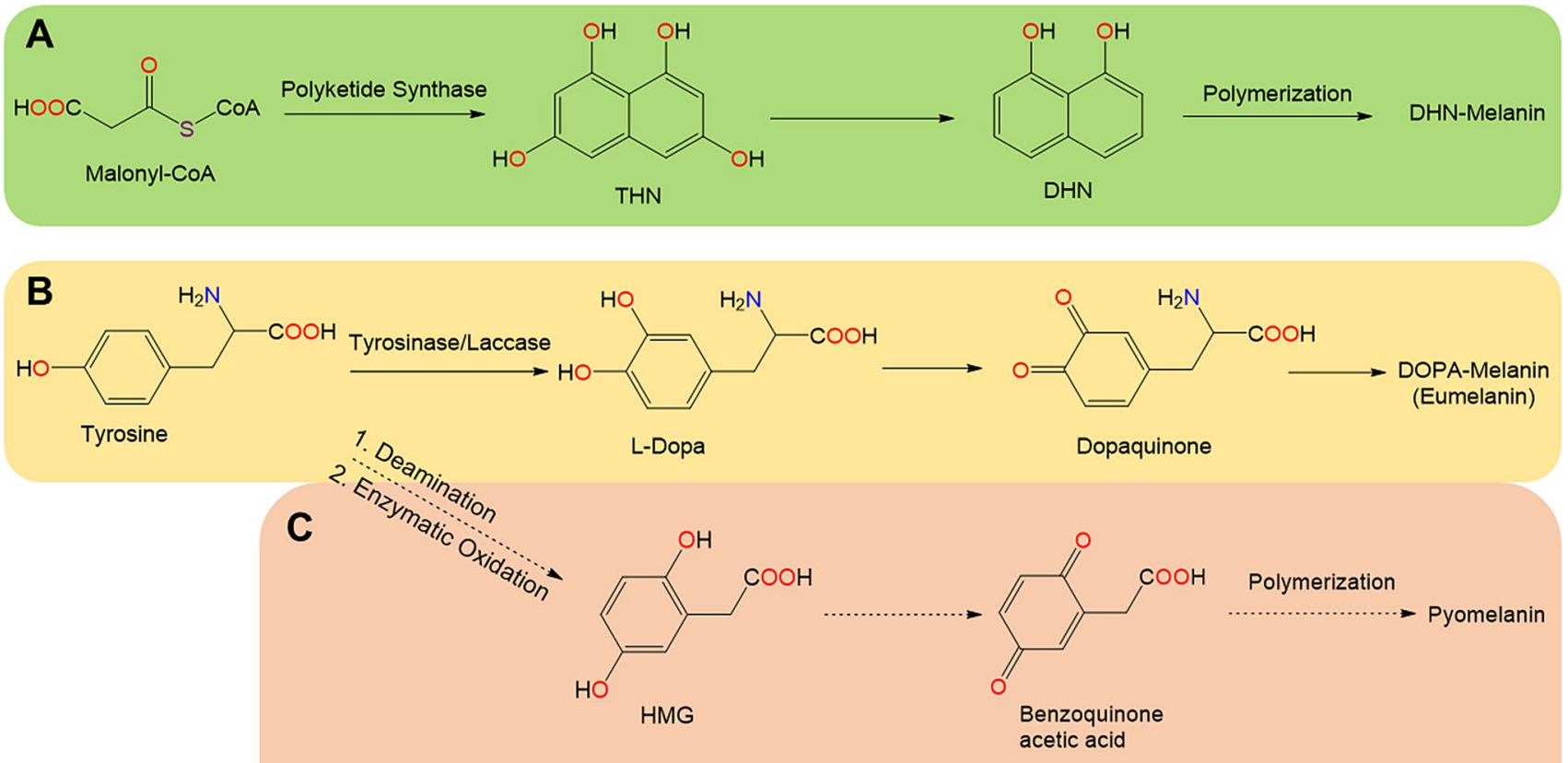

Altered metabolic routes due to enzymatic imbalances

Fig. 2 Schematic representation of melanin synthesis in bacteria and fungi, indicating key chemical transformations common to microbial melanin forming processes. a DHN-pathway; b DOPA-pathway; c In the event of enzymatic imbalances, altered metabolic pathway can occur, leading to different types of melanins, for example pyomelanin 
released by microorganisms during host defense (SchmalerRipcke et al. 2009; Almeida-Paes et al. 2012). Consequently, many microbes depend on exogenous tyrosine or tyrosine derivative substrates for melanin synthesis. This is of great interest for scientists that study microbial melanization since melanin is produced extracellularly and harsh extraction can therefore be avoided. Several bacteria and fungi in this category are summarized in Table 2.

Additionally, these characteristics allow considerable control of the yield and the type of resulting melanin. Although tyrosine is identified as the main melanin substrate, other catecholamines such as dopamine and norepinephrine can also be used as substrates. However, it is important to note that melanins resulting from different substrates may differ in structure due to various catabolic processes with different enzymes involved. This creates room for tuning the physicochemical properties and optimizing the production of microbial melanins.

The formation of melanin depends highly on the regulation of melanin synthesis enzymes, which is driven by multiple nutritional factors and physicochemical conditions. Peptone, glucose and yeast extract are widely chosen as carbon

Table 2 Studies focused on optimization of microbial melanin production

\begin{tabular}{|c|c|c|c|c|c|c|}
\hline Microorganisms & Melanin type & $\begin{array}{l}\text { Max. melanin } \\
\text { production/g L } \\
\text { (Incubation time / } \\
\text { days) }\end{array}$ & Tyrosine added & Metal ions added & Substrates & References \\
\hline \multicolumn{7}{|l|}{ Bacteria } \\
\hline $\begin{array}{l}\text { Actinoalloteichus } \\
\text { sp. MA-32 }\end{array}$ & DOPA & $0.1(7)$ & Yes & $\mathrm{Fe}, \mathrm{Mg}$ & Glycerol & $\begin{array}{l}\text { (Manivasagan et al. } \\
\text { 2013) }\end{array}$ \\
\hline Bacillus safensis & $\mathrm{Nd}$ & $6.9(24 \mathrm{~h})$ & None & None & Fruit waste extract & $\begin{array}{l}\text { (Tarangini and Mishra } \\
\text { 2014) }\end{array}$ \\
\hline $\begin{array}{l}\text { Brevundimonas sp. } \\
\text { SGJ }\end{array}$ & DOPA & $6.8(54 \mathrm{~h})$ & Yes & $\mathrm{Cu}$ & Tryptone & (Surwase et al. 2013) \\
\hline $\begin{array}{l}\text { Nocardiopsis alba } \\
\text { MSA10 }\end{array}$ & $\mathrm{Nd}$ & $3.4(7)$ & Yes & $\mathrm{Nd}$ & Sucrose & (Kiran et al. 2014) \\
\hline $\begin{array}{l}\text { Pseudomonas sp. } \\
\text { WH001 } 55\end{array}$ & $\mathrm{Nd}$ & $7.6(6)$ & Yes & None & Starch, yeast extract & (Kiran et al. 2017) \\
\hline $\begin{array}{l}\text { Pseudomonas } \\
\text { stutzeri HMGM-7 }\end{array}$ & DOPA & $7.2(3)$ & Yes & None & $\begin{array}{l}\text { Nutrient broth in sea } \\
\text { water }\end{array}$ & $\begin{array}{l}\text { (Ganesh Kumar et al. } \\
\text { 2013) }\end{array}$ \\
\hline $\begin{array}{l}\text { Streptomyces } \\
\text { glaucescens } \\
\text { NEAE-H }\end{array}$ & DOPA & $0.4(6)$ & Yes & $\mathrm{Fe}$ & Protease peptone & $\begin{array}{l}\text { (El-Naggar and El- } \\
\text { Ewasy 2017) }\end{array}$ \\
\hline $\begin{array}{l}\text { Streptomyces kathi- } \\
\text { rae SC-1 }\end{array}$ & DOPA & $13.7(5)$ & Yes & $\mathrm{Cu}$ & $\begin{array}{l}\text { Amylodextrine, yeast } \\
\text { extract }\end{array}$ & (Guo et al. 2014) \\
\hline $\begin{array}{l}\text { Streptomyces lusi- } \\
\text { tanus DMZ-3 }\end{array}$ & nd & $5.3(6)$ & Yes & $\mathrm{Cu}$ & Beef extract & $\begin{array}{l}\text { (Madhusudhan et al. } \\
\text { 2014) }\end{array}$ \\
\hline $\begin{array}{l}\text { Streptomyces sp. } \\
\text { ZL-24 }\end{array}$ & DOPA & $4.2(5)$ & None & $\mathrm{Fe}, \mathrm{Ni}$ & Soy peptone & (Wang et al. 2019) \\
\hline \multicolumn{7}{|l|}{ Fungi } \\
\hline Armillaria borealis & DOPA & $11.58(97)$ & Yes & $\mathrm{Cu}, \mathrm{Fe}, \mathrm{Mg}$ & $\begin{array}{l}\text { Glucose, yeast } \\
\text { extract }\end{array}$ & (Ribera et al. 2019) \\
\hline $\begin{array}{l}\text { Armillaria cepis- } \\
\text { tipes }\end{array}$ & DOPA & $27.98(161)$ & Yes & $\mathrm{Cu}, \mathrm{Fe}, \mathrm{Mg}$ & $\begin{array}{l}\text { Glucose, yeast } \\
\text { extract }\end{array}$ & (Ribera et al. 2019) \\
\hline Armillaria ostoyae & DOPA & $24.80(153)$ & Yes & $\mathrm{Cu}, \mathrm{Fe}, \mathrm{Mg}$ & $\begin{array}{l}\text { Glucose, yeast } \\
\text { extract }\end{array}$ & (Ribera et al. 2019) \\
\hline $\begin{array}{l}\text { Aspergillus fumiga- } \\
\text { tus }\end{array}$ & $\mathrm{Nd}$ & $0.01(10)$ & No & None & Dextrose, peptone & (Raman et al. 2015) \\
\hline $\begin{array}{c}\text { Auricularia } \\
\text { auricula }\end{array}$ & DOPA & $2.97(8)$ & Yes & $\mathrm{Mg}$ & Lactose, yeast extract & (Sun et al. 2016) \\
\hline $\begin{array}{l}\text { Daldinia concen- } \\
\text { trica }\end{array}$ & DOPA & $1.78(73)$ & Yes & $\mathrm{Cu}, \mathrm{Fe}, \mathrm{Mg}$ & $\begin{array}{l}\text { Glucose, yeast } \\
\text { extract }\end{array}$ & (Ribera et al. 2019) \\
\hline $\begin{array}{l}\text { Gliocephalotrichum } \\
\text { simplex }\end{array}$ & DOPA & $6.60(6)$ & Yes & $\mathrm{Cu}, \mathrm{Fe}$ & $\begin{array}{l}\text { Peptone, yeast } \\
\text { extract }\end{array}$ & (Jalmi et al. 2012) \\
\hline
\end{tabular}

$N d$ not defined 
and nitrogen sources. Recent studies have also exploited agricultural residues, such as fruit waste extract, corn steep liquor and wheat bran extract, to lower the production cost while ensuring the high yield of production (Hamano and Kilikian 2006; Silveira et al. 2008; Zou and Tian 2017). Copper is an important element for melanin production because of its role as a cofactor for laccases and tyrosinases (Sendovski et al. 2011; Reiss et al. 2013; Yang et al. 2017). Variation in the amount of added copper leads to irregular pigmentation in several fungal and bacterial species (Held and Kutzner 1990; Griffith et al. 2007). On the one hand, besides copper, other metals can also enhance melanin formation. A recent study by Wang et al. (2019) showed a strong increase in tyrosinase activity and melanin production driven by the addition of iron and nickel. On the other hand, the presence of metals may induce stress responses in microbes, resulting in melanin formation (Gowri and Srivastava 1996). In other cases, melanin synthesis is promoted by different kinds of stress, for instance: high temperature, nutrient-poor growth media, hyperosmotic pressure, etc. (Coyne and Al-Harthi 1992; Fogarty and Tobin 1996; Cordero and Casadevall 2017). Because of the multiple and diverse factors that affect melanin biosynthesis, there is no universal culture media or cultivation condition for growing melanogenic microorganisms. Instead, the composition and ratio of each component should be identified depending on the microbe. Similarly, environmental factors, i.e. temperature, $\mathrm{pH}$, the presence of oxygen and aeration, light, stress and irradiation during cultivation, can greatly affect the cell growth and pigment biosynthesis, and should be carefully considered. Some statistic tools such as the Taguchi method, the Plackett-Burman design, or the Response surface methodology are usually used to design multifactorial experiments and to evaluate the impact of each factor in the production process (Surwase et al. 2013; Saini and Melo 2015; Sun et al. 2016; El-Naggar and El-Ewasy 2017).

Previously, most melanin-related studies involving other microorganisms, such as Aspergillus carbonarius or Streptomyces glaucescens NEAE-H (El-Naggar and El-Ewasy 2017), could not achieve melanin suitable for industrial application yields $\left(<1 \mathrm{~g} \mathrm{~L}^{-1}\right.$ medium) even after optimizing the growth conditions. In contrast, studies focused on optimizing melanin production utilize fungi and bacteria with the ability to produce melanin via tyrosine transformation. The optimized protocols usually involve the exogenous supply of tyrosine, copper and/or other metal ions and show the possibility to produce melanin pigments in significant yields. For instance, melanin can now be produced by Armillaria cepistipes at gram-scale (28 $\mathrm{g} \mathrm{L}^{-1}$ medium) in laboratory condition, which paves the way for industrial scaling up and future applications of melanin (Ribera et al. 2019).

Last but not least, microbial melanin production can be further improved by applying genetic engineering techniques to increase the natural melanogenic capacity of some organisms or generating novel melanin-producing strains. The most common genetic modification to enhance/generate a production strain, targets the expression of genes encoding the enzymes involved in melanin formation, mostly tyrosinases. The latest advances in the generation of recombinant melanogenic strains and production processes were already summarized by (Martínez et al. 2019) and are not the focus of this review.

\section{Applications of microbial melanins}

In fungi and bacteria, melanins are usually reported for its important role in the virulence of pathogenic organisms (Jacobson 2000; Cordero and Casadevall 2017). With the advancement of new knowledge and technologies, melanin pigments can now be turned into valuable materials in various fields of green technology, materials science, biomedicine, cosmetics and environmental remediation (Fig. 3).

From a physicochemical viewpoint, melanin is a natural "sunscreen" that absorbs the broadband of UV-visible light spectrum. In addition to blocking UV light, this pigment is a powerful antioxidant. Melanin also exhibits a hydration-dependent semiconductor-like behavior. As such, it is evaluated as a component for organic electronic devices (Bothma et al. 2008; Kim et al. 2013). Other advantages of microbial melanin are its bioavailability, biocompatibility and biodegradability, making it a promising candidate for biomedical applications; for example, implantable devices (Vahidzadeh et al. 2018). In another type of application, melanin has been employed for the environmentally benign synthesis of silver nanostructures. These melanin-mediated silver nanostructures show broad-spectrum antimicrobial activity against food pathogens and have potential uses in the food and health industries (Kiran et al. 2014; Patil et al. 2018). Dermal and cosmetic applications of melanin include its use for sunscreen and hair dyeing. Melanin can act as metal chelators, which can be employed in environmental applications. By incorporating fungal melanin with other polymers such as polycaprolactone and polyurethane, the melanin-based composites can remove up to $94 \% \mathrm{~Pb}$ (II) in water systems (Tran-Ly et al. 2020). Although there are a lot of studies reporting the potential applications of melanin, they are mostly in the developmental stage and have not yet been commercialized. In the era of transition towards sustainable materials, microbial melanin research has not yet reached its full potential.

\section{Conclusions and outlook}

Melanins are a unique class of natural pigments that can be considered functional materials for multiple potential applications in industry. The future of melanin-based 


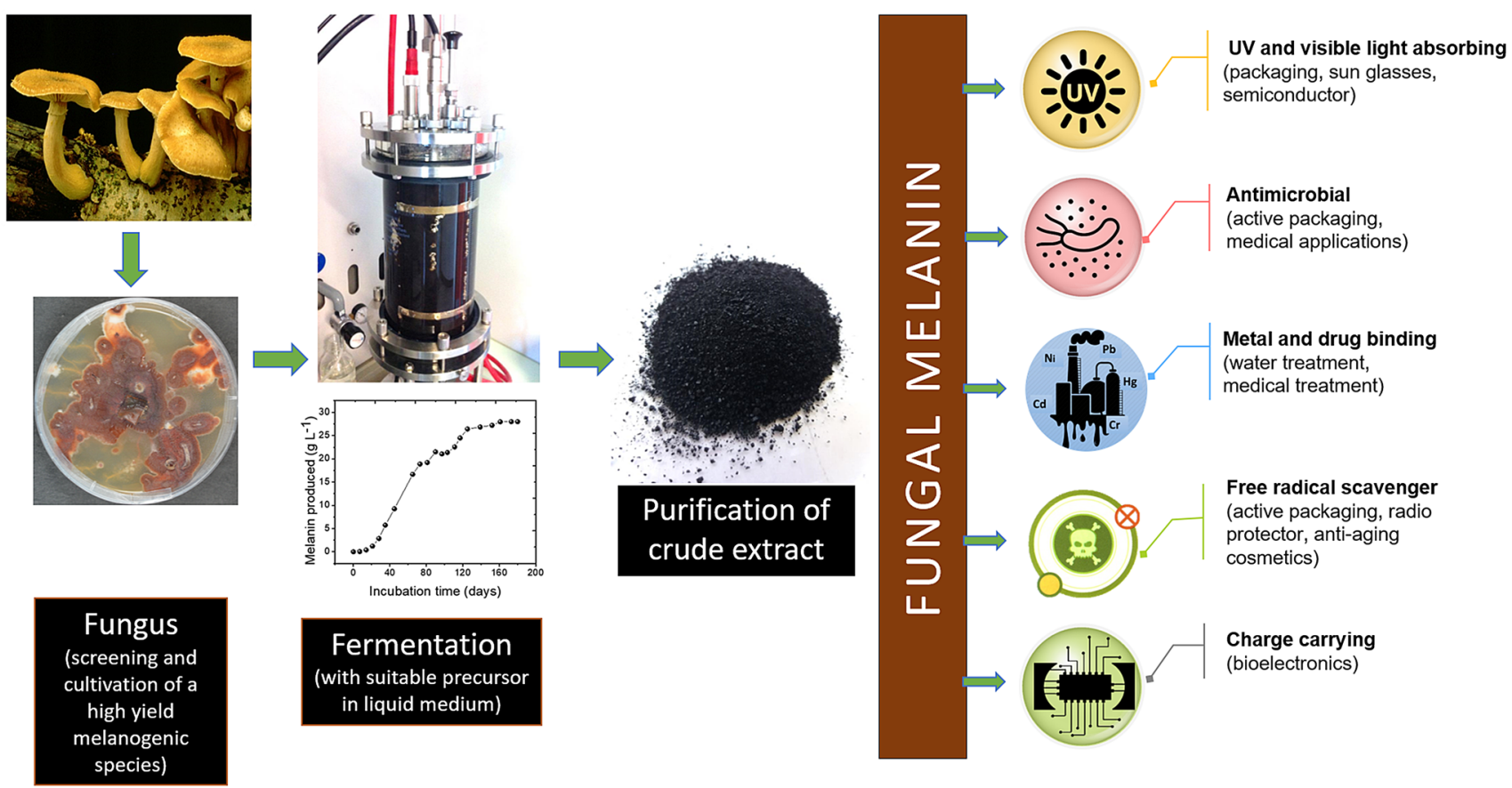

Fig. 3 Biotechnological production of fungal melanin and its potential applications

materials and technology development depends on the ability to produce melanin at a large scale with a chemically defined structure and low cost. As discussed in this review, conventional approaches are the isolation of melanins from natural sources like sepia ink and chemical synthesis. They are, however, unsustainable and difficult to scale up. A feasible alternative approach is using melanogenic microorganisms and melanin precursors. Although no universal protocol is available, good tips for producing high-yield microbial melanins are: (i) choosing the microorganisms that can produce melanin extracellularly from the exogenous substrate, and (ii) improving the metabolic process by adding tyrosine and copper to the culture media. However, it is worth pointing out that melanins comprise a chemically-diverse group of polymers. So far, most of the published works on microbial melanin production focused on eumelanin. However, the chemical diversity of melanin, which can be controlled by the supplied melanin precursors, has not yet been fully explored. Furthermore, the accumulated knowledge on the biochemistry and genetic engineering of melanin in various organisms can contribute to the direct manipulation and enhancement of melanin production. With this perspective, melanin can be used beyond basic research and encourage more researchers from industry to deploy bio-inspired melanin-based materials for biomedical, environmental and technological applications.
Funding Open Access funding provided by Lib4RI - Library for the Research Institutes within the ETH Domain: Eawag, Empa, PSI \& WSL.

Open Access This article is licensed under a Creative Commons Attribution 4.0 International License, which permits use, sharing, adaptation, distribution and reproduction in any medium or format, as long as you give appropriate credit to the original author(s) and the source, provide a link to the Creative Commons licence, and indicate if changes were made. The images or other third party material in this article are included in the article's Creative Commons licence, unless indicated otherwise in a credit line to the material. If material is not included in the article's Creative Commons licence and your intended use is not permitted by statutory regulation or exceeds the permitted use, you will need to obtain permission directly from the copyright holder. To view a copy of this licence, visit http://creativecommons.org/licenses/by/4.0/.

\section{References}

Almeida-Paes R, Nosanchuk JD, Zancope-Oliveira RM (2012) Fungal melanins: biosynthesis and biological functions. Melanin: biosynthesis, functions and health effects. Nova Science Publishers Inc., Hauppauge, pp 77-107

Bernsmann F, Frisch B, Ringwald C, Ball V (2010) Protein adsorption on dopamine-melanin films: role of electrostatic interactions inferred from $\zeta$-potential measurements versus chemisorption. J Colloid Interface Sci 344:54-60. https://doi.org/10.1016/j. jcis.2009.12.052

Borovanskỳ J, Riley PA (2011) History of melanosome research. Melanins and melanosomes: biosynthesis, biogenesis, physiological, and pathological functions. Wiley-VCH, Weinheim, pp 1-19 
Bothma JP, De Boor J, Divakar U et al (2008) Device-quality electrically conducting melanin thin films. Adv Mater 20:3539-3542. https://doi.org/10.1002/adma.200703141

Brenner M, Hearing VJ (2008) The protective role of melanin against UV damage in human skin. Photochem Photobiol 84:539-549. https://doi.org/10.1111/j.1751-1097.2007.00226.x

Bridelli MG, Crippa PR (2010) Infrared and water sorption studies of the hydration structure and mechanism in natural and synthetic melanin. J Phys Chem B 114:9381-9390. https://doi.org/10.1021/ jp101833k

Cordero RJB, Casadevall A (2017) Functions of fungal melanin beyond virulence. Fungal Biol Rev 31:99-112. https://doi.org/10.1016/j. fbr.2016.12.003

Coyne VE, Al-Harthi L (1992) Induction of melanin biosynthesis in Vibrio cholerae. Appl Environ Microbiol 58:2861-2865. https:// doi.org/10.1128/aem.58.9.2861-2865.1992

d'Ischia M, Wakamatsu K, Napolitano A et al (2013) Melanins and melanogenesis: methods, standards, protocols. Pigment Cell Melanoma Res 26:616-633. https://doi.org/10.1111/pcmr.12121

d'Ischia M, Napolitano A, Ball V et al (2014) Polydopamine and eumelanin: from structure-property relationships to a unified tailoring strategy. Acc Chem Res 47:3541-3550. https://doi. org/10.1021/ar500273y

d'Ischia M, Pezzella A, Napolitano A et al (2015) Melanins and melanogenesis: from pigment cells to human health and technological applications. Pigment Cell Melanoma Res 28:520-544. https://doi.org/10.1111/pcmr.12393

Eisenman HC, Casadevall A (2012) Synthesis and assembly of fungal melanin. Appl Microbiol Biotechnol 93:931-940. https:// doi.org/10.1007/s00253-011-3777-2

El-Naggar NEA, El-Ewasy SM (2017) Bioproduction, characterization, anticancer and antioxidant activities of extracellular melanin pigment produced by newly isolated microbial cell factories Streptomyces glaucescens NEAE-H. Sci Rep 7:42129. https:// doi.org/10.1038/srep42129

Fogarty RV, Tobin JM (1996) Fungal melanins and their interactions with metals. Enzyme Microb Technol 19:311-317. https://doi. org/10.1016/0141-0229(96)00002-6

Ganesh Kumar C, Sahu N, Narender Reddy G et al (2013) Production of melanin pigment from Pseudomonas stutzeri isolated from red seaweed Hypnea musciformis. Lett Appl Microbiol 57:295-302. https://doi.org/10.1111/lam.12111

Glass K, Ito S, Wilby PR et al (2012) Direct chemical evidence for eumelanin pigment from the Jurassic period. Proc Natl Acad Sci USA 109:10218-10223. https://doi.org/10.1073/pnas.11184 48109

Gowri PM, Srivastava S (1996) Encapsulation as a response of Azospirillum brasilense $\mathrm{sp} 7$ to zinc stress. World J Microbiol Biotechnol 12:319-322. https://doi.org/10.1007/BF00340207

Griffith GW, Easton GL, Detheridge A et al (2007) Copper deficiency in potato dextrose agar causes reduced pigmentation in cultures of various fungi. FEMS Microbiol Lett 276:165-171. https://doi. org/10.1111/j.1574-6968.2007.00923.x

Guo J, Rao Z, Yang T et al (2014) High-level production of melanin by a novel isolate of Streptomyces kathirae. FEMS Microbiol Lett 357:85-91. https://doi.org/10.1111/1574-6968.12497

Hamano PS, Kilikian BV (2006) Production of red pigments by Monascus ruber in culture media containing corn steep liquor. Braz $\mathrm{J}$ Chem Eng 23:443-449. https://doi.org/10.1590/S0104-66322 006000400002

Held T, Kutzner HJ (1990) Transcription of the tyrosinase gene in Streptomyces michiganensis DSM 40015 is induced by copper and repressed by ammonium. J Gen Microbiol 136:12. https:// doi.org/10.1099/00221287-136-12-2413
Jacobson ES (2000) Pathogenic roles for fungal melanins. Clin Microbiol Rev 13:708-717. https://doi.org/10.1128/ CMR.13.4.708-717.2000

Jalmi P, Bodke P, Wahidullah S, Raghukumar S (2012) The fungus Gliocephalotrichum simplex as a source of abundant, extracellular melanin for biotechnological applications. World J Microbiol Biotechnol 28:505-512. https://doi.org/10.1007/s11274-011-0841-0

Ju KY, Lee Y, Lee S et al (2011) Bioinspired polymerization of dopamine to generate melanin-like nanoparticles having an excellent free-radical-scavenging property. Biomacromolecules 12:625632. https://doi.org/10.1021/bm101281b

Karlsson O, Lindquist NG (2016) Melanin and neuromelanin binding of drugs and chemicals: toxicological implications. Arch Toxicol 90:1883-1891. https://doi.org/10.1007/s00204-016-1757-0

Kim YJ, Wu W, Chun SE et al (2013) Biologically derived melanin electrodes in aqueous sodium-ion energy storage devices. Proc Natl Acad Sci USA 110:20912-20917. https://doi.org/10.1073/ pnas. 1314345110

Kiran GS, Dhasayan A, Lipton AN et al (2014) Melanin-templated rapid synthesis of silver nanostructures. J Nanobiotechnol 12:1. https://doi.org/10.1186/1477-3155-12-18

Kiran GS, Jackson SA, Priyadharsini S et al (2017) Synthesis of Nm-PHB (nanomelanin-polyhydroxy butyrate) nanocomposite film and its protective effect against biofilm-forming multi drug resistant Staphylococcus aureus. Sci Rep 7:9167. https://doi. org/10.1038/s41598-017-08816-y

Le Na NT, Duc Loc S, Minh Tri NL et al (2019) Nanomelanin potentially protects the spleen from radiotherapy-associated damage and enhances immunoactivity in tumor-bearing mice. Materials (Basel) 12:1725. https://doi.org/10.3390/ma12101725

Lee H, Dellatore SM, Miller WM, Messersmith PB (2007) Musselinspired surface chemistry for multifunctional coatings. Science 318:426-430. https://doi.org/10.1126/science.1147241

Ligonzo T, Ambrico M, Augelli V et al (2009) Electrical and optical properties of natural and synthetic melanin biopolymer. J Non Cryst Solids 355:1221-1226. https://doi.org/10.1016/j.jnoncrysol .2009 .05 .014

Liu Y, Simon JD (2003) Isolation and biophysical studies of natural eumelanins: applications of imaging technologies and ultrafast spectroscopy. Pigment Cell Res 16:606-618. https://doi.org/10.1 046/j.1600-0749.2003.00098.x

Liu Y, Kempf VR, Nofsinger JB et al (2003) Comparison of the structural and physical properties of human hair eumelanin following enzymatic or acid/base extraction. Orig Res Artic 16:355-365. https://doi.org/10.1034/j.1600-0749.2003.00059.x

Liu Y, Ai K, Liu J et al (2013) Dopamine-melanin colloidal nanospheres: an efficient near-infrared photothermal therapeutic agent for in vivo cancer therapy. Adv Mater 25:1353-1359. https://doi. org/10.1002/adma.201204683

Liu Y, Ai K, Lu L (2014) Polydopamine and its derivative materials: synthesis and promising applications in energy, environmental, and biomedical fields. Chem Rev 114:5057-5115. https://doi. org/10.1021/cr400407a

Madhusudhan DN, Mazhari BBZ, Dastager SG, Agsar D (2014) Production and cytotoxicity of extracellular insoluble and droplets of soluble melanin by Streptomyces lusitanus DMZ-3. Biomed Res Int 2014:306895. https://doi.org/10.1155/2014/306895

Manivasagan P, Venkatesan J, Senthilkumar K et al (2013) Isolation and characterization of biologically active melanin from Actinoalloteichus sp. MA-32. Int J Biol Macromol 58:263-274. https://doi. org/10.1016/j.ijbiomac.2013.04.041

Martínez LM, Martinez A, Gosset G (2019) Production of melanins with recombinant microorganisms. Front Bioeng Biotechnol 7:285. https://doi.org/10.3389/fbioe.2019.00285 
Nosanchuk JD, Casadevall A (2003) The contribution of melanin to microbial pathogenesis. Cell Microbiol 5:203-223. https://doi.org /10.1046/j.1462-5814.2003.00268.x

Nosanchuk JD, Stark RE, Casadevall A (2015) Fungal melanin: what do we know about structure? Front Microbiol 6:1463. https://doi. org/10.3389/fmicb.2015.01463

Novellino L, Napolitano A, Prota G (2000) Isolation and characterization of mammalian eumelanins from hair and irides. Biochim Biophys Acta 1475:295-306. https://doi.org/10.1016/S0304 $-4165(00) 00080-5$

Patil S, Sistla S, Bapat V, Jadhav J (2018) Melanin-mediated synthesis of silver nanoparticles and their affinity towards tyrosinase. Appl Biochem Microbiol 54:163-172. https://doi.org/10.1134/S0003 683818020096

Pavan ME, López NI, Pettinari MJ (2020) Melanin biosynthesis in bacteria, regulation and production perspectives. Appl Microbiol Biotechnol 104:1821-1822. https://doi.org/10.1007/s00253-01910245-y

Pezzella A, d'Ischia M, Napolitano A et al (1997) An integrated approach to the structure of sepia melanin. Evidence for a high proportion of degraded 5,6-Dihydroxyindole-2-carboxylic acid units in the pigment backbone. Tetrahedron 53:8281-8286. https ://doi.org/10.1016/S0040-4020(97)00494-8

Plonka PM, Grabacka M (2006) Melanin synthesis in microorganisms-biotechnological and medical aspects. Acta Biochim Pol 53:429-443. https://doi.org/10.18388/abp.2006_3314

Pralea I-E, Moldovan R-C, Petrache A-M et al (2019) From extraction to advanced analytical methods: the challenges of melanin analysis. Int J Mol Sci 20:3943. https://doi.org/10.3390/ijms20163943

Prota G (1995) The chemistry of melanins and melanogenesis. In: Herz W, Kirby GW, Moore RE, Steglich WTC (eds) Fortschritte der Chemie organischer Naturstoffe. Progress in the chemistry of organic natural products / Progrès dans la chimie des substances organiques naturelles. Springer, Vienna, pp 93-148

Raman NM, Shah PH, Mohan M, Ramasamy S (2015) Improved production of melanin from Aspergillus fumigatus AFGRD105 by optimization of media factors. AMB Express 5:72. https://doi. org/10.1186/s13568-015-0161-0

Reiss R, Ihssen J, Richter M et al (2013) Laccase versus laccase-like multi-copper oxidase: a comparative study of similar enzymes with diverse substrate spectra. PLoS One 8:6. https://doi. org/10.1371/journal.pone.0065633

Ribera J, Panzarasa G, Stobbe A et al (2019) Scalable biosynthesis of melanin by the basidiomycete Armillaria cepistipes. J Agric Food Chem 67:132-139. https://doi.org/10.1021/acs.jafc.8b05071

Saini AS, Melo JS (2015) One-pot green synthesis of eumelanin: process optimization and its characterization. RSC Adv 5:4767147680. https://doi.org/10.1039/c5ra01962a

Schmaler-Ripcke J, Sugareva V, Gebhardt P et al (2009) Production of pyomelanin, a second type of melanin, via the tyrosine degradation pathway in Aspergillus fumigatus. Appl Environ Microbiol 75:493-503. https://doi.org/10.1128/AEM.02077-08

Sendovski M, Kanteev M, Ben-Yosef VS et al (2011) First structures of an active bacterial tyrosinase reveal copper plasticity. J Mol Biol 405:227-237. https://doi.org/10.1016/j.jmb.2010.10.048
Silveira ST, Daroit DJ, Brandelli A (2008) Pigment production by Monascus purpureus in grape waste using factorial design. LWT Food Sci Technol 41:170-174. https://doi.org/10.1016/j. lwt.2007.01.013

Solano F (2014) Melanins: skin pigments and much more-types, structural models, biological functions, and formation routes. New J Sci 2014:498276. https://doi.org/10.1155/2014/498276

Solano F (2017) Melanin and melanin-related polymers as materials with biomedical and biotechnological applications - cuttlefish ink and mussel foot proteins as inspired biomolecules. Int J Mol Sci 18:1561. https://doi.org/10.3390/ijms18071561

Sun S, Zhang X, Chen W et al (2016) Production of natural edible melanin by Auricularia auricula and its physicochemical properties. Food Chem 196:486-492. https://doi.org/10.1016/j.foodc hem.2015.09.069

Surwase SN, Jadhav SB, Phugare SS, Jadhav JP (2013) Optimization of melanin production by Brevundimonas sp. SGJ using response surface methodology. 3 Biotech 3:187-194. https://doi. org/10.1007/s13205-012-0082-4

Tarangini K, Mishra S (2014) Production of melanin by soil microbial isolate on fruit waste extract: two step optimization of key parameters. Biotechnol Rep 4:139-146. https://doi.org/10.1016/j. btre.2014.10.001

Toledo AV, Franco MEE, Yanil Lopez SM et al (2017) Melanins in fungi: types, localization and putative biological roles. Physiol Mol Plant Pathol 99:2-6. https://doi.org/10.1016/j. pmpp.2017.04.004

Tran-Ly AN, Ribera J, Schwarze FWMR et al (2020) Fungal melanin-based electrospun membranes for heavy metal detoxification of water. Sustain Mater Technol 23:e00146. https://doi. org/10.1016/j.susmat.2019.e00146

Vahidzadeh E, Kalra AP, Shankar K (2018) Melanin-based electronics: from proton conductors to photovoltaics and beyond. Biosens Bioelectron 122:127-139. https://doi.org/10.1016/j.bios.2018.09.026

Wang L, Li Y, Li Y (2019) Metal ions driven production, characterization and bioactivity of extracellular melanin from Streptomyces sp. ZL-24. Int J Biol Macromol 123:521-530. https://doi. org/10.1016/j.ijbiomac.2018.11.061

Xiao M, Chen W, Li W et al (2018) Elucidation of the hierarchical structure of natural eumelanins. J R Soc Interface 15:20180045. https://doi.org/10.1098/rsif.2018.0045

Yang J, Li W, Bun Ng T et al (2017) Laccases: production, expression regulation, and applications in pharmaceutical biodegradation. Front Microbiol 8:832. https://doi.org/10.3389/fmicb.2017.00832

Zhang F, Kearns SL, Orr PJ et al (2010) Fossilized melanosomes and the colour of Cretaceous dinosaurs and birds. Nature 463:10751078. https://doi.org/10.1038/nature08740

Zou Y, Tian M (2017) Fermentative production of melanin by Auricularia auricula. J Food Process Preserv 41:e12909. https://doi. org/10.1111/jfpp.12909

Publisher's Note Springer Nature remains neutral with regard to jurisdictional claims in published maps and institutional affiliations. 